\title{
Clarification of Issues Raised in the Editorial "A New Age for Cancer Information Seeking: Are We Better Off Now?"
}

To the Editor:-I read with great interest the editorial by Paul R. Helft, $\mathrm{MD}^{1}$ about my article "Frustrated and Confused: The American Public Rates its Cancer-Related InformationSeeking Experiences." ${ }^{2}$ My coauthors and I are very appreciative that the journal considered our findings worthy of an editorial. However, I did come across a few inaccuracies in the editorial that I discuss below and provide needed clarification.

1. On the first page, the editorial states "... the sampled cohort may not be educationally representative of US adults in general, as the 2006 US Census data suggests that more than $80 \%$ of US adults over the age of 20 are high school graduates, whereas only $32 \%$ of the HINTS survey cohort reported having graduated from high school."

Unfortunately, this statement is incorrect and has perhaps resulted from a simple misinterpretation of data in Table 1 of our paper that described the HINTS sample. As shown in the table, the education breakup of the HINTS sample was less than high school: $16.9 \%$, high school graduate: $32.0 \%$, some college: $26.8 \%$, and college graduate: $24.3 \%$. Thus, $83.1 \%$ (and not $32 \%$ ) of the HINTS sample had at least a high school education; a figure very similar to the Census statistic of $80 \%$ cited by Dr. Helft. In fact, one of the hallmarks of the HINTS program is that it is representative of the U.S. population and is the only nationally representative survey of its kind to provide insights into the cancer information-seeking practices and experiences of the American public.

2. Also on the first page, it is stated that "The authors do not indicate whether respondents who had never sought cancer information differed in any substantial ways from those who had sought cancer information at any time in their lives."

We do in fact provide this information. This was precisely the first of three specific aims of our paper, and Table 2 of the paper identifies respondent characteristics that distinguish between those who had ever looked for cancer information themselves from those who had never sought cancer information themselves. Perhaps we could have labeled the title of the table better to facilitate interpretation.

3. On the second page, the first subheading reads: "Is it a positive or negative finding that so few individuals who sought cancer information did so first from sources other than their health care provider?"

This heading is inconsistent with the commentary that follows it and is perhaps a result of a minor editing error. The words "so few" should actually have been "so many" or "most." As the editorial correctly summarizes our findings, we found that only about $11 \%$ of the information seekers turned to their health care providers first and the remaining 89\%, hence most and not so few first turned to sources other than their health care provider for cancer-related information.

I appreciate the opportunity to clarify these inaccuracies in what is otherwise an excellent editorial and is very much appreciated by myself and my coauthors.

Sincerely,

Neeraj K. Arora, PhD, Division of Cancer Control and Population Sciences, National Cancer Institute, 6130 Executive Blvd, EPN 4005, MSC 7344, Bethesda, MD 20892-7344, USA; (e-mail: aroran@mail.nih.gov).

\section{REFERENCES}

1. Helft PR. A new age for cancer information seeking: are we better off now? J Gen Intern Med. DOI 10.1007/s11606-007-0496-6.

2. Arora NK, Hesse BW, Rimer BK, Viswanath K, Clayman ML, Croyle RT. Frustrated and confused: the American public rates its cancer-related information seeking experiences. J Gen Intern Med. DOI 10.1007/ s11606-007-0406-y.

J Gen Intern Med 23(6):893

DOI: $10.1007 / \mathrm{s} 11606-008-0531-2$

(C) Society of General Internal Medicine 2008 